\title{
STANDPUNKT
}

\section{Das Strafvollzugsgesetz darf weder zerstückelt noch ausgehöhlt werden}

\author{
Heinz Cornel
}

$\mathrm{D}$ er Wahlkampf ist vorbei und wenn diese Zeilen gedruckt erscheinen, wird es wohl eine große Koalition geben, die als eines ihrer ersten Projekte die Föderalismusreform wieder aufnehmen will. Ein Teil der gemeinsamen Pläne der jetzigen Ministerkollegen Müntefering und Stoiber bestand im Dezember 2004 darin, die Gesetzgebungskompetenz für den Strafvollzug vom Bund auf die Länder zu übertragen und damit das Strafvollzugsgesetz als gemeinsame Grundlage des deutschen Strafvollzugs zugunsten von 16 Einzelregelungen aufzugeben.

Mehr als 100 Strafrechtswissenschaftler, Strafvollzugsrechtler und Kriminologen hatten sich damals dagegen ausgesprochen, die Rechtseinheit im Strafvollzugsrecht, aber auch von materiellem Recht, Verfahrens- und Vollzugsrecht aufzulösen. Zahlreiche Fachverbände und die großen Kirchen sowie Rechtspolitiker aller Parteien sendeten kritische Stellungnahmen zu diesen Plänen. Der damalige parlamentarische Geschäftsführer der CDU/CSU-Bundestagsfraktion Dr. Norbert Röttgen teilte zusammenfassend mit, dass unter den Rechtspolitikern aller Fraktionen im deutschen Bundestag erhebliche Bedenken gegen die Übertragung der Bundeskompetenzen für den Strafvollzug auf die Länder bestünden und die bayerische Staatsministerin der Justiz sprach davon, dass sich das "moderne Strafvollzugsgesetz« im Großen und Ganzen bewährt habe. Offensichtlich musste das in den 70er Jahren einstimmig verabschiedete Gesetz erst mit einem Bein im Grabe stehen, um wieder etwas Wertschätzung zu erfahren.

Aber noch ist es nicht zu spät. Man schnürt nicht das ganze von der Föderalismuskommission verpackte Paket auf, wenn man einen Fehler zugibt - zumal wenn kaum noch jemand hinter der damaligen Entscheidung steht und sie bestenfalls als Ergebnis eines Kompromisses für »vertretbar « (so die Bundesministerin der Justiz Brigitte Zypries) gehalten wird.

Aufschnüren oder nicht - das ist keine taktisch politische Frage, denn über Grundgesetzänderungen muss aus guten Gründen un- ter ausdrücklicher Nennung des Wortlautes des Grundgesetzes mit Zweidrittelmehrheiten des Bundestages und des Bundesrates entschieden werden. Welchen Einfluss werden die Rechtspolitiker der Bundestagsfraktionen aus Regierung und Opposition haben? Werden sie den fachlichen Argumenten und denen der Gleichbehandlung zum Durchbruch verhelfen und das »Bauernopfer «, wie es der CDU-Abgeordnete Siegfried Kauder nannte, zurückweisen?

Abgestimmt wird aber nicht nur im Bundestag, sondern auch im Bundesrat muss eine Zustimmung von zwei Dritteln der Stimmen zustande kommen. Die FDP hat sich in den letzten Monaten am deutlichsten für die Beibehaltung der Gesetzgebungskompetenz für den Strafvollzug beim Bund ausgesprochen. Im Bundesrat kann ohne die Zustimmung der Landesregierungen, an denen die FDP beteiligt ist, keine Zweidrittelmehrheit zustande kommen.

Wer hätte vor einem Jahr gedacht, dass es - sollte die Föderalismuskommission bei ihren Plänen bleiben und der Bundestag mit der nötigen Anzahl seiner Mitglieder zustimmen - es an der ehemaligen Möchtegern-18\%-Spaßpartei liegen kann, ob das Strafvollzugsgesetz zerstückelt und ausgehöhlt oder die Rechtseinheit im bundesdeutschen Strafvollzug beibehalten wird. Nimmt die FDP ihren in letzter Zeit wieder verstärkt geäußerten Anspruch als Rechtstaatspartei ernst, dann darf sie diesbezüglich nicht umfallen. 